\title{
ALGUNAS OBSERVACIONES SOBRE LAS SEMEJANZAS Y LAS DIFERENCIAS DE LA LINGÜÍSTICA ESTRUCTURAL APLICADA A LA SINTAXIS DE LA ORACIÓN NOMINAL EN LENGUA ÁRABE
}

Luisa María Arvide Cambra

\section{INTRODUCCIÓN}

Para el lingüista danés Louis Hjelmslev, que fue el padre de la glosemática y el que más difundió y desarrolló las teorías de Ferdinand de Saussure, toda lengua es un código. Hjelmslev trató de sustraer la ciencia lingüística de toda apreciación subjetiva y se esforzó por establecer una especie de álgebra del lenguaje, es decir, una red de definiciones que habría de formar un sistema que pudiese servir de modelo a la descripción de idiomas en particular.

En sus Prolegómenos a una teoría del lenguaje afirmaba que lo constante en una lengua puede hallarse en las relaciones, en las dependencias mutuas de los varios elementos que lo componen.

Los elementos propios del lenguaje no son sonidos ni letras ni significados, sino los relata que éstos representan. La definición y descripción de las relaciones entre tales elementos constituyen la tarea de la lingüística.

Lo que tienen todos los lenguajes en común es el principio estructural; lo que los distingue es la adaptación de tal principio, en su caso particular. Tanto la semejanza como la diferencia se deben a la forma, no a la sustancia.

La lengua es forma, no sustancia. La sustancia, en tanto que no es estructurada, no pasa de ser una masa amorfa. En cuanto a la estructura de una lengua, ésta es una red de dependencias o una red de funciones.

La Sintaxis es el estudio de las relaciones en el seno de un enunciado y el estudio de los tipos de enunciado. La Sintaxis funcional se aplica al estudio de los diversos tipos de predicación, descubriendo las relaciones recíprocas entre las palabras (formas sintagmáticas) y sus relaciones estructurales.

El sistema es sistema de posibilidades, de coordenadas que indican caminos abiertos y cerrados. Puede considerarse como conjunto de imposiciones pero también como conjunto 
de libertades, puesto que admite infinitas realizaciones y sólo exigen que no afecten a las condiciones funcionales del estamento lingüístico.

Todo análisis lingüístico tiende a fundarse en puntos de vista que conducen a considerar como formas tanto el contenido como la expresión. De este modo, el funcionamiento conduce al estructuralismo.

Las estructuras pueden estudiarse en sí mismas y la lengua se considera, entonces, como un sistema abstracto de puras relaciones.

El célebre lingüista francés André Martinet, el creador de la teoría de la doble articulación del lenguaje, afirmaba en Quelques traits généraux de la Syntax, Free University Quarterly 1.959, que había que rendirse a la evidencia de que, cuando se pasa de una lengua a otra, no cambian sólo las formas y las palabras, no cambian sólo las nociones; cambia también la elección de las relaciones que deben expresarse.

La funcionalidad, que deriva de estas nuevas tendencias lingüísticas estructurales, se impone como técnica de análisis morfosintáctico o gramatical en todas las lenguas. Y, por supuesto, la lengua árabe no se ha librado tampoco de este análisis metodológico.

A ese respecto, nadie ignora la existencia de serias y rigurosas investigaciones desde supuestos llamémosles "occidentales"y, también, desde posiciones que podríamos denominar "árabes": ambas técnicas serán citadas en este trabajo en lo sucesivo como A y B, respectivamente.

Lo curioso comienza cuando se aplican estos procedimientos sobre una base de elementos distintos, tomados muchos de ellos de la tradición histórica y que, al no coincidir a nivel aislado, terminan convirtiéndose en órganos de un miembro aparentemente diferente pero, en el fondo, igual.

En otras palabras, la mezcla de influencias de una fuerte tradición gramatical, iniciada fundamentalmente con Sibawayhi, y de una nueva corriente lingüística, la estructuralfuncional, importada de Occidente, ha dado lugar entre los árabes a una interesante visión sintáctica de la lengua, semejante y, a la vez, diferente a la de los investigadores de Europa y de América.

Este trabajo aborda y trata algunas de estas cuestiones aplicadas a la oración nominal en lengua árabe.

\section{Vocabulario de base empleado en este trabajo}

- اسم

- preposición

- جمملة: oración

-جملة اسميّة: oración nominal 
- جملة بسيطة: oración simple

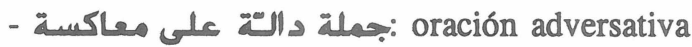

- مجملة ظلير فيّة : oración subordinada circunstancial

- oración verbal

- مصلة مركتبة: oración compuesta

- circunstancial de modo

- حر ف: partícula

- مخبر: atributo

- فاعل: sujeto

- فعل : verbo

- فعل الوزم: verbo intransitivo

- "فعل منعد: verbo transitivo

- فعل مجحهول: verbo pasivo

- مبتدأ sujeto oración nominal

- منمتمات: complementos

- مجحرور: genitivo

- مر فوع :مرور: nominativo

- فم: circunstancial

-منعول به: complemento directo

- منعول ثانيا: $2^{\circ}$ complemento directo; suplemento

- مئعول: 'circunstancial de causa

معنعول فيه circunstancial de tiempo y lugar

- منعول مطلق: acusativo interno

- معنعول معهد: circunstancial de compañía

- منصور: acusativo

- sujeto paciente

Abreviaturas empleadas en este trabajo

- CC: Complemento circunstancial

- PN: Predicado nominal 
- PV: $\quad$ Predicado verbal

- SN: $\quad$ Sintagma nominal

- SNSU: Sintagma nominal sujeto

- SV: $\quad$ Sintagma verbal

- SVP: $\quad$ Sintagma verbal predicado

$-V: \quad$ Verbo

- ATR: Atributo

\section{EXPOSICIÓN Y DESARROLLO}

\subsection{Antecedentes}

En primer lugar, conviene definir los conceptos de oración, oración simple y oración compuesta.

En Lógica, se llama oración (o proposición) a la expresión verbal de un juicio, siendo el juicio la relación entre dos conceptos: sujeto y predicado.

Ejemplo:

$$
\begin{aligned}
& \text { El niño juega } \\
& \text { * El niño: SNSU } \\
& \text { * juega: SVP }
\end{aligned}
$$

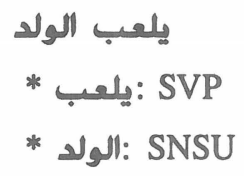

El núcleo de la unidad sintáctica es, para nosotros, un verbo en forma personal. Todos los elementos, palabras, frases $u$ oraciones enteras, que se relacionan de modo inmediato $o$ mediato con un verbo en forma personal, constituyen con él una oración.

La oración es la unidad del habla correspondiente a otra psíquica, formada por elementos que están en régimen funcional y estructurado, con independencia fonética y gramatical, y autonomía de significación.

La oración consta de una serie de unidades, palabras organizadas en un sistema coherente, las partes o categorías de la oración.

Dichas unidades están montadas sobre el eje sintagma nominal - sintagma verbal predicado, base de la oración.

Por sintagma se entiende "mínima unidad de función". Es una unidad sintáctica o sintagmática que puede ser simple o compleja (grupos sintagmáticos) y en él distinguimos el núcleo y los elementos adyacentes que se añaden a él por el proceso de expansión, término acuñado por André Martinet. 
El núcleo de un sintagma nominal es siempre un nombre y el del verbal, un verbo.

El sintagma nominal puede desempeñar las funciones de sujeto, atributo, complemento directo, complemento indirecto o complemento circunstancial. El sintagma verbal realiza la función del predicado.

Oración simple es la que consta de un solo nexus o relación sujeto/predicado, y puede ser nominal y verbal.

Ejemplo de oración nominal:

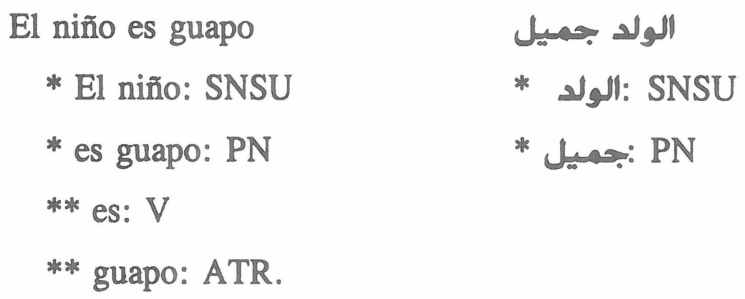

Ejemplo de oración verbal:

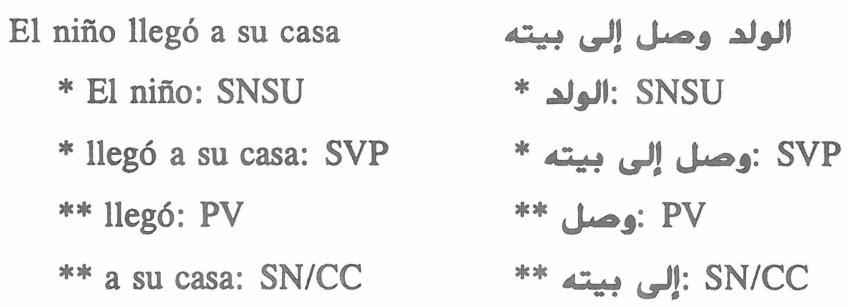

En general, pues, entendemos por oración nominal aquélla en cuya constitución no aparece ningún verbo, como elemento de la misma, de cualquier tipo que sea. Equivale a nuestras oraciones atributivas o copulativas con los verbos haber, ser y/o estar, en tiempo presente, cuya misión en ellas se reduce a servir de nexo o unión entre el sujeto y el predicado, sin añadir nada al significado de la oración.

La oración nominal simple puede ir precedida por una partícula, "ن, que significa ciertamente, aunque puede también quedar sin traducción. Dicha partícula obliga a poner el sujeto en caso acusativo [منصوب], si pertenece a una categoría gramatical declinable.

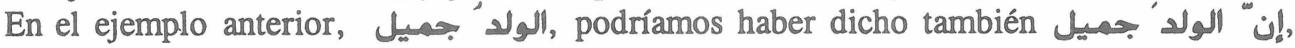
siendo su traducción la misma, esto es, el niño es guapo o ciertamente el niño es guapo.

Cuando la oración no anuncia una cualidad del sujeto sino que expresa un fenómeno, una transformación en la que el sujeto participa, recibe el nombre de predicativa u oración verbal. 
En esta clase de oraciones, la palabra esencial del predicado es el verbo, con independencia de su colocación en la oración, bien delante bien detrás del sujeto, por eso se dice que el predicado es verbal; en tanto que en las atributivas, el predicado es nominal.

Ejemplo:
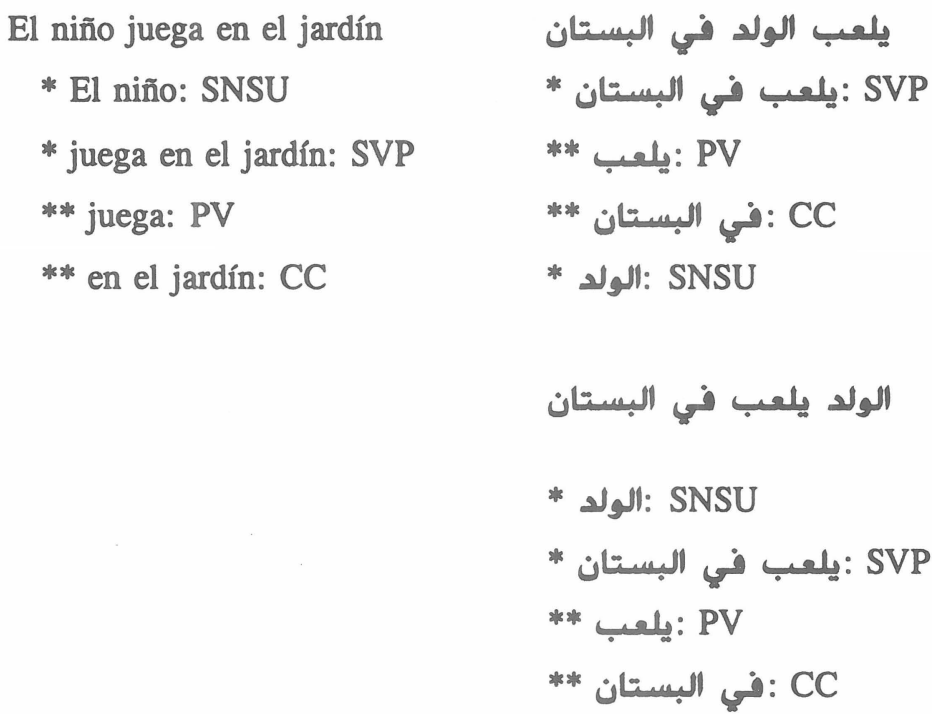

Para nosotros, la presencia del verbo es, pues, esencial para que haya oración, y con independencia del lugar de su colocación en la misma, ésta es considerada siempre oración verbal.

Oración compuesta es aquélla que consta de más de un nexus o relación sujeto/predicado.

En este caso, hay que ver los vínculos existentes entre ellos, es decir, entre los nexus. En general, pueden estar:

- Yuxtapuestos: relaciones al mismo nivel sintáctico (más usual en lengua árabe actual)

Ejemplo:

$$
\text { Llegó, vió, venció }
$$$$
\text { وصل، رأى، نصر }
$$

- Coordinados: relaciones al mismo nivel sintáctico

Ejemplo:

$$
\text { Llegó, vió y venció }
$$$$
\text { وصل ورأى و نصر }
$$

- Subordinados: relaciones a distinto nivel sintáctico 
Ejemplo:

Llegó para visitar a su madre

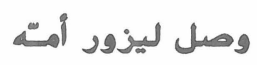

Una vez aclarados los conceptos, volvamos a la oración nominal sobre la cual gira este trabajo.

Recordemos que por oración nominal entendemos, en general, aquélla en cuya constitución no aparece ningún verbo como elemento de la misma, de cualquier tipo que sea.

Sin embargo, los árabes tienen otra noción de esta clase de oraciones. Dicha noción ha sido heredada -como ya he hecho constar- de la tradición gramatical histórica y como consecuencia de un punto de vista totalmente descriptivo.

Para ellos, una oración nominal es sencillamente aquélla que comienza:

1) por un nombre, haya o no verbo

Ejemplos:

El niño es pequeño

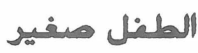

El hombre va a la ciudad

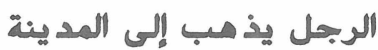

¿Quién eres tú?

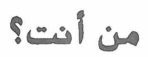

El niño está delante de la casa

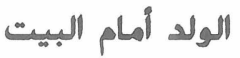

Sus elementos son: مبتداً y خبرا.

Veámos los ejemplos de antes:

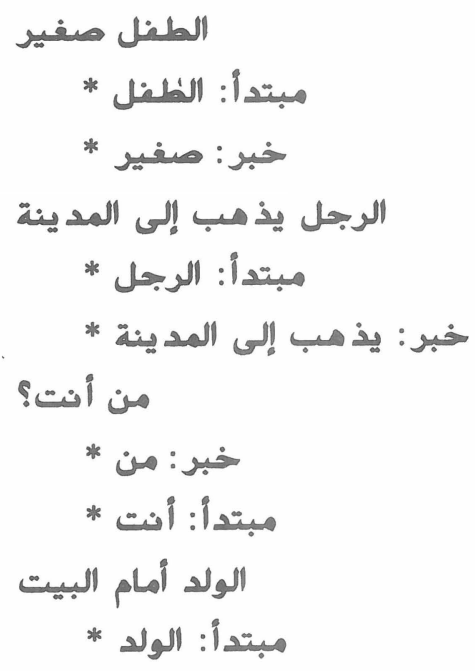




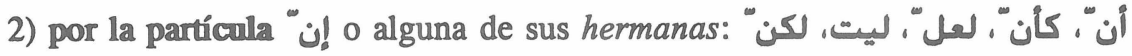
Ejemplos:

$\mathrm{El}$ niño es pequeño

El hombre va a la ciudad

¿Quién eres tú?

El niño está delante de la casa
إن” الطفل صفير إن" الو.جل يذ مب إلى المد ينة إنة

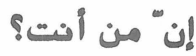
إنَ الولد أمام البيت من إن

Sus elementos son: "حمبر إن" النم إن.

Veámos los ejemplos de anteriores:

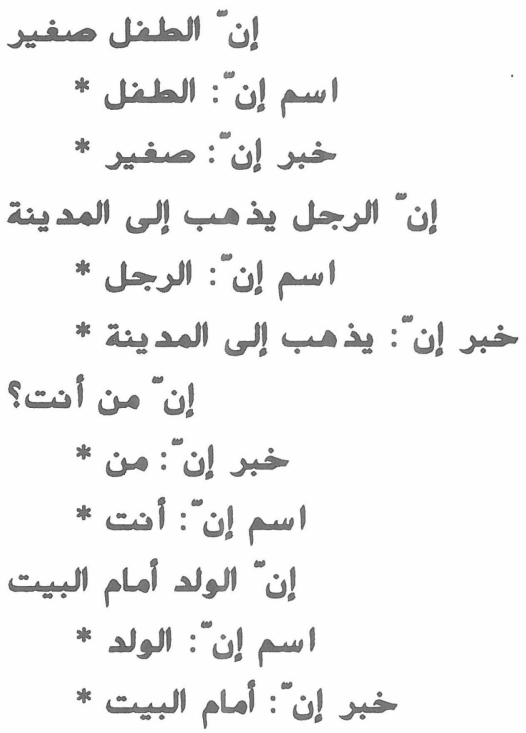

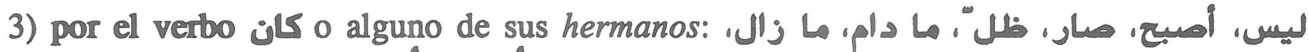

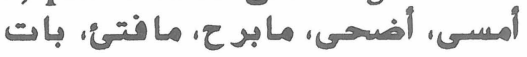

Ejemplos:

El niño era pequeño

El hombre iba a la ciudad

El niño estaba delante de la casa

Sus elementos son: اسم كان أهبر كان الهم
كان الطنل صنير' كان الرجل يذ هب إلى المد ينة كان الولد أمام البيت 
Veámos los ejemplos anteriores:

$$
\begin{aligned}
& \text { كان الطفل صغير' } \\
& \text { * اسم كان :الطعل انطل }
\end{aligned}
$$

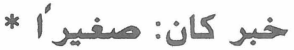

$$
\begin{aligned}
& \text { كان الرجل هذ مبب إلى المد ينة }
\end{aligned}
$$

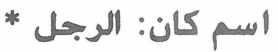

$$
\begin{aligned}
& \text { * خبر كان: يذ هب إلى المد ينة المانية } \\
& \text { كان الولد أمام البيت المديت } \\
& \text { * اسب كان: الولد الوند } \\
& \text { * خبر كان: أمام البيت }
\end{aligned}
$$

Por otra parte, por oración verbal o predicativa los gramáticos árabes entienden toda aquélla que comienza por un verbo.

Ejemplos:

El hombre va a la ciudad

Las niñas comieron pan

$$
\text { يذ ميب الرجل إلى الهد ينة }
$$

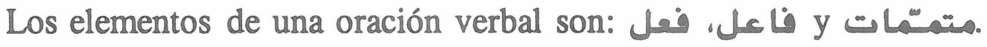

منعول مطلق، مغعول به، منعول فيه، مغعول معه، الحال،Lueden ser متمستمات Los مغنعول أجهله

Veámos los ejemplos anteriores:

$$
\begin{aligned}
& \text { يذّ هب الرجل إلى المد ينة }
\end{aligned}
$$

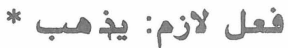

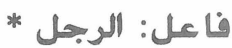

$$
\begin{aligned}
& \text { * منعول فيه: إلى المد ينة: الرجل } \\
& \text { أكلت البنات خحبز المدئ } \\
& \text { * فعل منتعد } \\
& \text { * فاعل: البنات معند }
\end{aligned}
$$

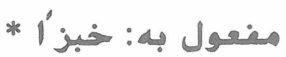

\subsection{Consecuencias y conclusiones}

Considerando estas cuestiones teóricas de base y teniendo en cuenta dichas posturas y postulados y precisamente al entrar en escena los métodos estructurales, ocurre que nos 
encontramos con análisis sintácticos diversos y diferentes, denominados -como ya señaléa partir de ahora A (análisis occidentales) y B (análisis árabes).

Puede suceder:

I) Que encontremos oraciones nominales compuestas en claras situaciones de oración verbal simple:

Ia) cuando la oración comienza por el sujeto

Ejemplo:

El hombre va a la ciudad

$$
\text { الرجهل يذْ مب إلى المد ينة }
$$

A: Oración verbal simple porque hay un solo verbo, en este caso intransitivo.

$$
\begin{aligned}
& \text { جملة فعليقة بسيطة: الرجل يذّب إلى المدينة } \\
& \text { * ناعل: الرجل }
\end{aligned}
$$

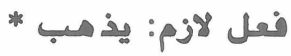

$$
\begin{aligned}
& \text { * منعول فيه إلى المد يندة }
\end{aligned}
$$

B: Oración nominal compuesta. Es nominal, porque comienza por un nombre; y compuesta, porque el حبر está desarrollado, a su vez, en forma de oración, en este caso verbal por ir iniciada por un verbo.

$$
\begin{aligned}
& \text { جملة اسميّة مركَّة: الرجل يذهب هب إلى المد ينّة }
\end{aligned}
$$

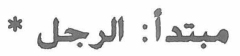

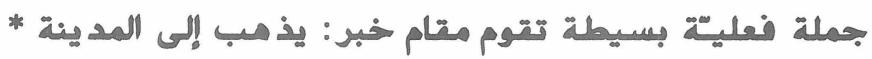

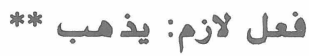

$$
\begin{aligned}
& \text { ** منعول فيه: إلى المد ينة }
\end{aligned}
$$

Ib) cuando la oración comienza por "ن! o alguna de sus hermanas.

Ejemplo:

Los campesinos han sembrado los campos إن" الفلاًّمين قد بزروا الحقول A: Oración verbal simple, porque hay un solo verbo, en este caso transitivo. E1 sujeto va en acusativo por ser el régimen de la partícula "ن! .

$$
\begin{aligned}
& \text { جملة فعليَّة بسصطة: إن" النلاًّحين قد بزروا الحمقول }
\end{aligned}
$$

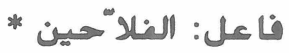

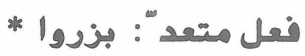

$$
\begin{aligned}
& \text { * منعول به: الحقول مندول }
\end{aligned}
$$


B: Oración nominal compuesta. Es nominal, porque comienza por "ن!; y compuesta, porque el "حبر إن está, a su vez, desarrollado en forma de oración, en este caso verbal por estar iniciada por un verbo.

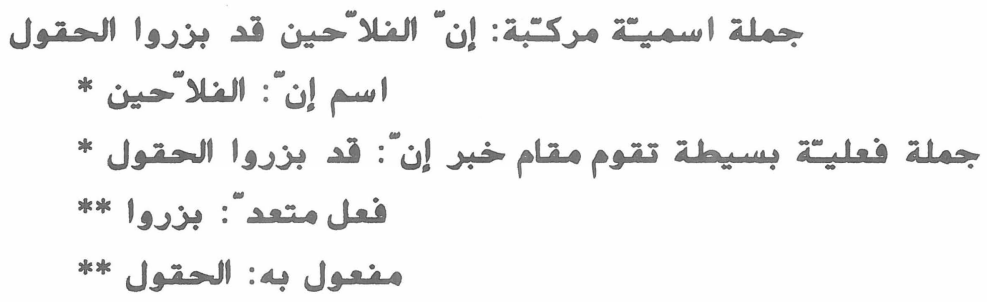

Ic) cuando la oración comienza por كان, al ser usado como auxiliar en tiempos como el pretérito imperfecto y el pretérito pluscuamperfecto; también sucede esto con con sus hermanos.

Ejemplo:

كان المعلتم كتب شيئا في الكتاب El maestro había escrito algo en el libro A: Oración verbal simple, porque hay un solo verbo, en este caso transitivo; كان es empleado como auxiliar para formar un tiempo compuesto, el pretérito pluscuamperfecto.

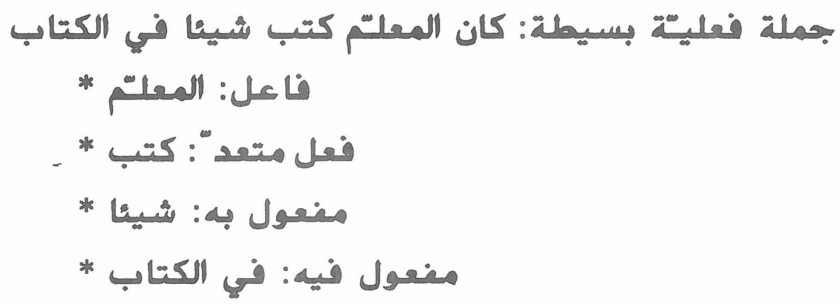

B: Oración nominal compuesta. Es nominal, porque comienza por كان; y compuesta, porque el حفبر كان está, a su vez, desarrollado en forma de oración, en este caso verbal por ir iniciada por un verbo.

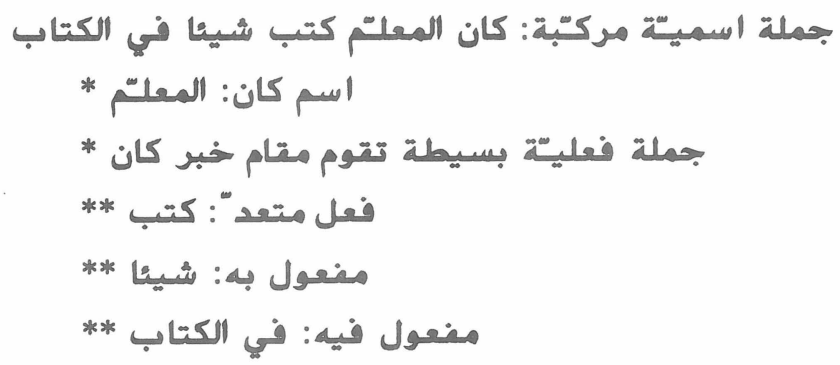

II) Que se den distintos análisis sintácticos de oraciones compuestas: 
Ejemplo:

Quien estudia aprueba

$$
\text { إن" من يدور سن هينجح }
$$

A: Oración verbal compuesta. El sujeto está desarrollado en forma de oración, en este caso relativa: Oración Subordinada Subjetiva o de Sujeto.

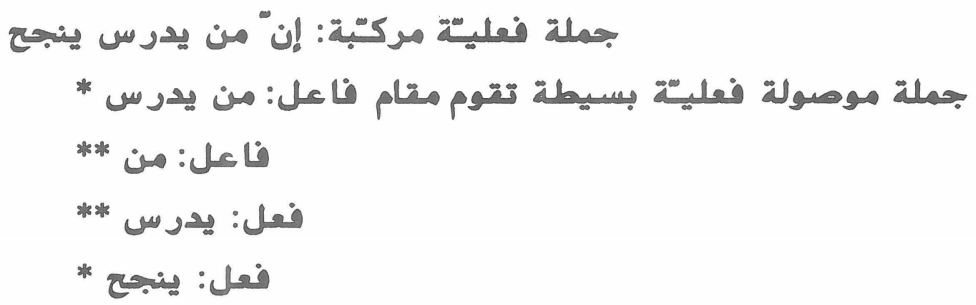

B: Oración nominal compuesta. Es nominal porque comienza por "ن; y doblemente compuesta, porque tanto el " خبر إن" como elán desarrollados en forma de oración; por otra parte el "حبر إن " حبر es también una oración nominal, porque comienza por el pronombre من; y compuesta, porque el está desarrollado en forma de oración, en este caso verbal por ir iniciada por un verbo.

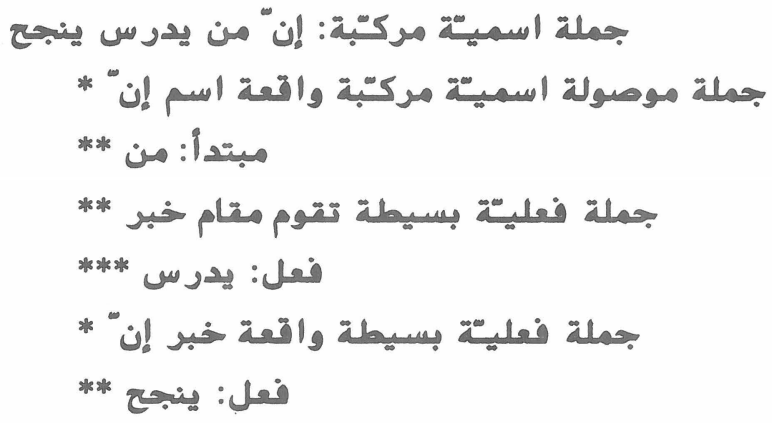

III) Que se den idénticos análisis sintácticos de oraciones compuestas, pero de diferente clase, por ser distintos sus elementos.

Ejemplo:

أن أسير في الصحصر إ تعب

A: Oración nominal compuesta atributiva. El sujeto está desarrollado en forma de oración: Oración Subordinada Subjetiva.

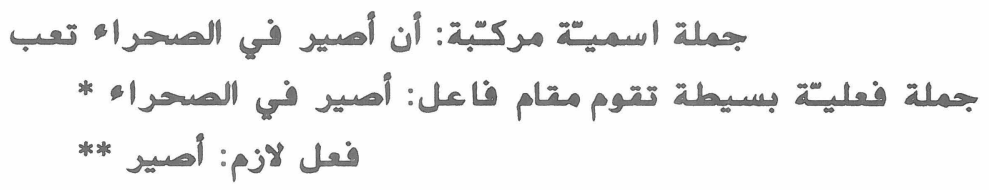




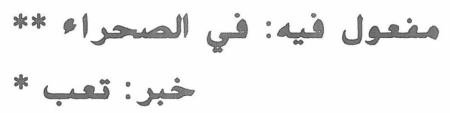

B: Oración nominal compuesta. El مبتد en este caso verbal por ir iniciada por un verbo.

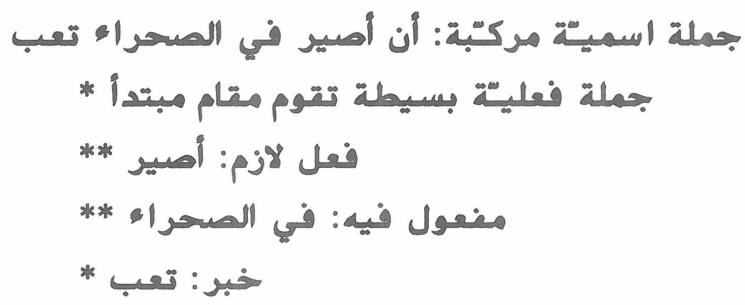

IV) Que si se invierte el orden de los elementos sujeto y predicado, en algunas de las oraciones explicadas, puede darse el curioso caso de requerir un análisis sintáctico distinto en el supuesto B y coincidir, por tanto, con el de A.

Ejemplos:

[El hombre va a la ciudad]

en lugar de

[El hombre va a la ciudad]

B: No tenemos oración nominal compuesta sino una oración verbal simple. Es verbal, porque comienza por verbo; y simple, porque no hay ningún elemento oracional desarrollado, a su vez, en forma de oración.

$$
\begin{aligned}
& \text { جملة فعليثة بسيطة: يذ مبب الرجل إلى المدينة }
\end{aligned}
$$

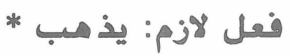

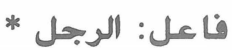

$$
\begin{aligned}
& \text { * منعول فيه: إلى المد ينة: } \\
& \text { [Los campesinos han sembrado los campos] }
\end{aligned}
$$

en lugar de

[Los campesinos han sembrado los campos] B: No tenemos una oración nominal compuesta sino una oración verbal simple. Es verbal, porque comienza por el verbo; y simple porque ninguno de sus elementos está desarrollado, a su vez, en forma de oración.

جملة فعليّة بسيطة: قد بزر الفلاّحون الحقول 


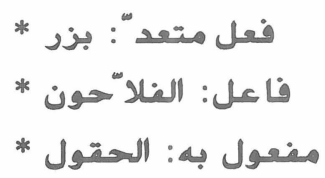

Una mención aparte requieren las llamadas partículas hermanas de "ن! incluída ella misma, como nexos de oraciones subordinadas, o de oraciones coordinadas adversativas en el caso de "لكن; pues, al ser considerada toda oración iniciada por alguna de ellas como una oración nominal, los análisis sintácticos cambian de tal manera que, incluso, son definidas de distinta forma.

Ejemplos:

Se dice que el examen fue difícil يقال إن" الإمتحان كان صعبا

A: Oración verbal compuesta. El sujeto está desarrollado en forma de oración: Oración Subordinada Subjetiva, en este caso atributiva o copulativa.

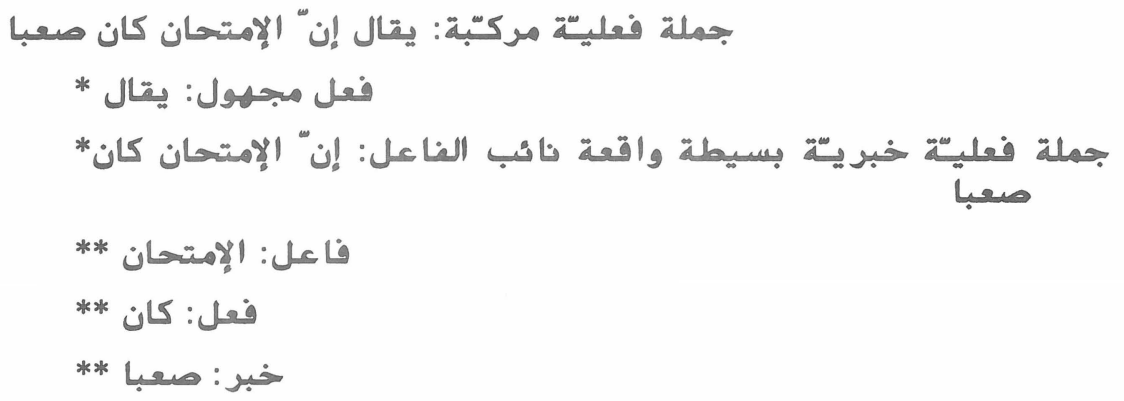

B: Oración verbal compuesta. Es verbal porque comienza por verbo y es doblemente compuesta porque el sujeto paciente está desarrollado en forma de oración y dentro de ella, a su vez, hay otra oración desempeñando la función de هبر إن

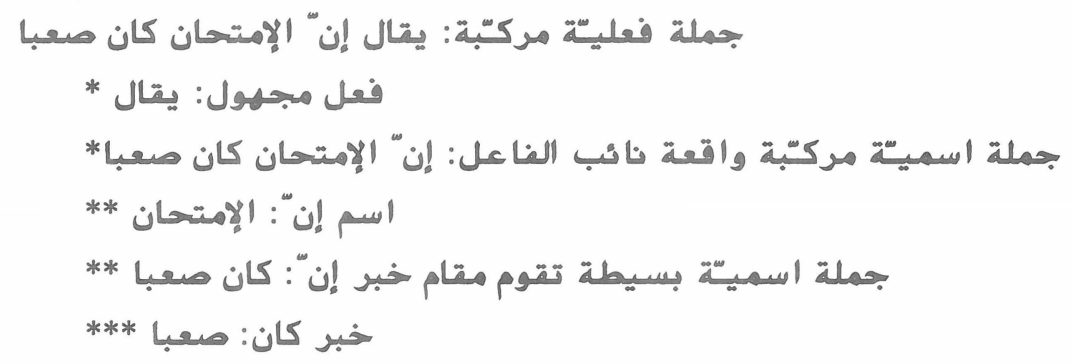

La revista Las Pirámides ha mencionado que Egipto detendrá la producción

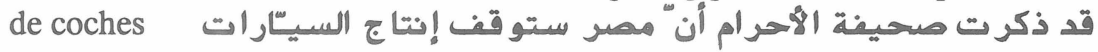


A: Oración verbal compuesta. El complemento directo está desarrollado en forma de oración: Oración Subordinada Objetiva, Completiva o de Complemento Directo.

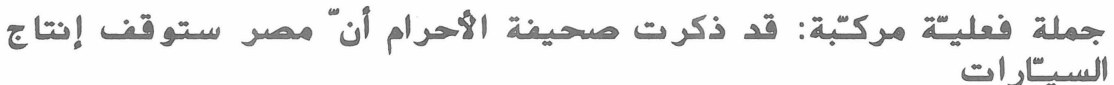

$$
\begin{aligned}
& \text { * فعل متعد": ذكر ت }
\end{aligned}
$$

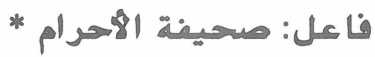

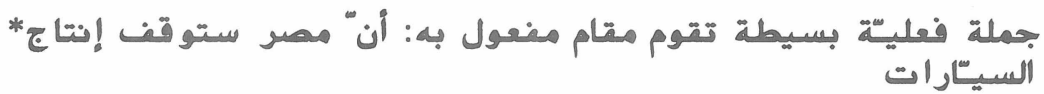

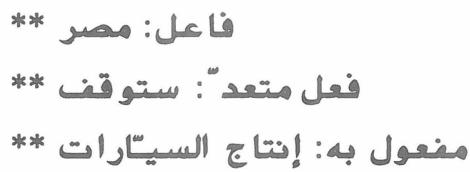

B: Oración verbal compuesta. Es verbal porque comienza por verbo y es doblemente compuesta porque, dentro de la oración subordinada completiva, hay otra oración desempeñando la función de "حبر أن

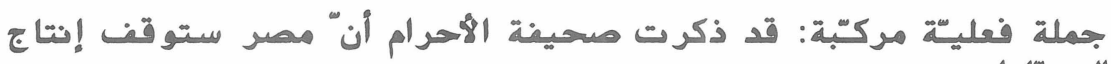

$$
\begin{aligned}
& \text { السيّار ات فعليت } \\
& \text { *عل منتعدّ": ذكر ت }
\end{aligned}
$$

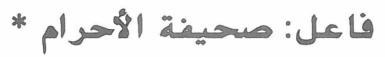

$$
\begin{aligned}
& \text { جملة اسميّة مركتبة تقوم مقام مفعول به: أن" مصر ستو قف إنتاج: } \\
& \text { السيّارات }
\end{aligned}
$$

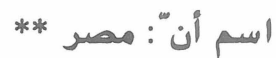

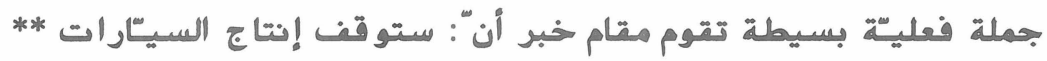

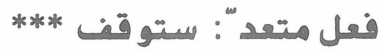

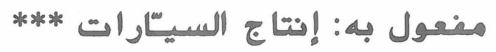

زر ت المد ينة لكنّي لم أذ مب إلى السوق A: Oración verbal compuesta coordinada adversativa (al mismo nivel sintáctico).

$$
\begin{aligned}
& \text { جملة فعليَّة مركَّبة: زرت المد ينة لكنّي لم أذ هب إلى السيوق } \\
& \text { * جملة فعليّة بسيطة: زرت ت المدينة }
\end{aligned}
$$

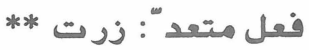




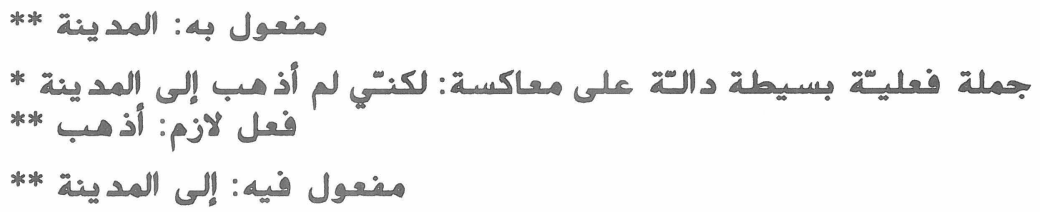

B: Oración verbal compuesta. Es verbal porque comienza por verbo y es doblemente compuesta porque el 2 está desarrollado, a su vez, en forma de oración.

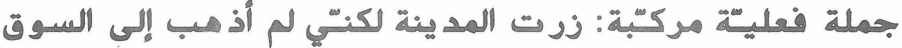

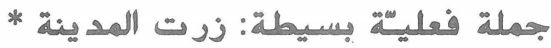

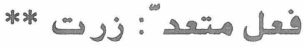

$$
\begin{aligned}
& \text { مفعول به: المد ينة م*ن رتح }
\end{aligned}
$$

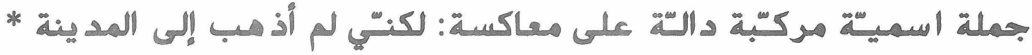

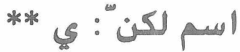

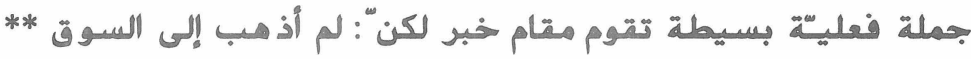

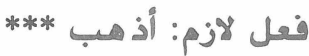

$$
\begin{aligned}
& \text { منعول فيه: إلى السيوق نمقن }
\end{aligned}
$$

El maestro informó al rey que los niños sabían leer

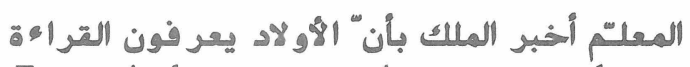

B: Oración nominal compuesta. Es nominal, porque comienza por nombre; y doblemente compuesta, porque el dentro de ella, hay otras dos oraciones más: una desempeña la función de segundo complemento directo o de suplemento; la otra realiza la función de "حْبر أن

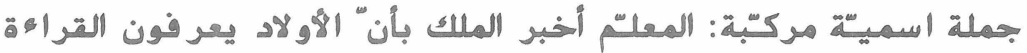

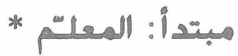

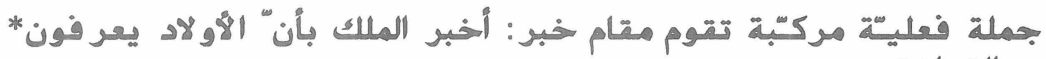

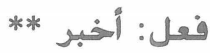

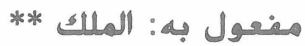

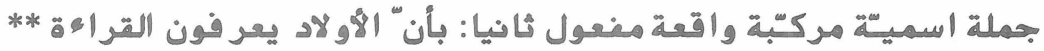

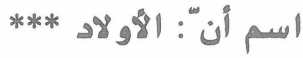

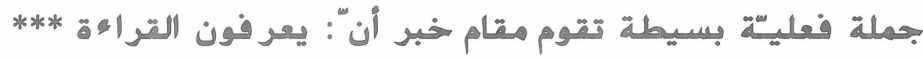

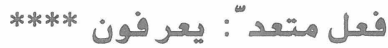




$$
\text { منعول به: القراءة }
$$

Nótese que si se hubiera invertido el orden de los elementos (sujeto y verbo), es decir, si hubiéramos dicho أخبر المعلتم .الملك بأن" الأولاد يعر فون التراءة con el mismo significado indicado antes, el análisis sintáctico habría variado y habría sido: Oración verbal compuesta; verbal, porque comienza por verbo, y doblemente compuesta, porque el segundo complemento directo está desarrollado en forma de oración, así como el "حبر أن

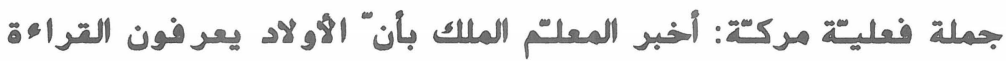

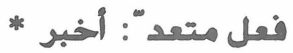

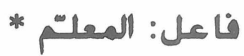

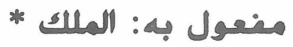

$$
\begin{aligned}
& \text { جملة اسميتة مركتبة تقوم مقام منعول ثانيا: بأن" الأولاد يعر فون* مون }
\end{aligned}
$$

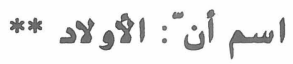

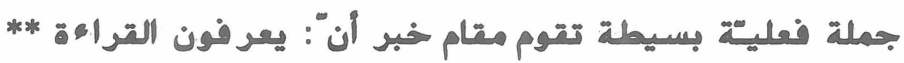

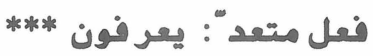

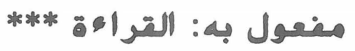

A: Oración verbal compuesta. El suplemento o segundo complemento directo está desarrollado en forma de oración: Oración Subordinada de Suplemento o de Segundo Complemento Directo, en ambos casos.

$$
\begin{aligned}
& \text { جملة فعليّة مركَّة: أحبر المعلّم الملك بأن" الأولاد يعر فون التراهة }
\end{aligned}
$$

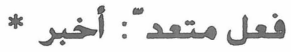

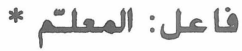

$$
\begin{aligned}
& \text { * منعول به: الملك }
\end{aligned}
$$

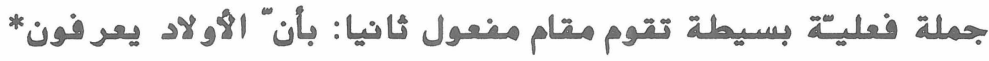

$$
\begin{aligned}
& \text { القراءة } \\
& \text { *ناعل: الأو لاد }
\end{aligned}
$$

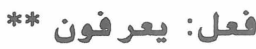

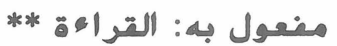

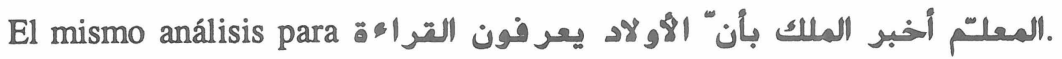

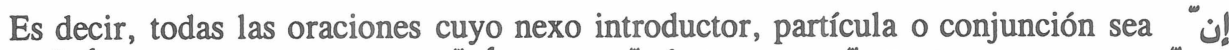
(que), "أن (que) -o sus variantes "أن (que), "إن (porque), "أن (puesto que)- y (pero, sin embargo), y tengan, a su vez, verbo propio, pasan a ser oraciones nominales 
compuestas en los análisis sintácticos denominados árabes y significados en este trabajo como $\mathrm{B}$, debido al proceso o mecanismo lingüístico de la funcionalidad.

Por el contrario, como hemos podido comprobar esto no sucede en los análisis sintácticos denominados occidentales y significados en este trabajo como A.

Una última consideración: como se ha visto a lo largo de este trabajo, la lengua árabe es el mismo objeto de análisis en ambos métodos, así como sus técnicas de investigación; pero, como ya he señalado, las descripciones son sensiblemente diferentes por partir de elementos teóricos de base distintos.

Todo ello sucede porque la visión que cada pueblo tiene de la realidad abstracta y concreta, o simplemente la visión del mundo, es diferente; por eso decimos que hay varias culturas, si bien en las visiones del mundo hay, por supuesto, también semejanzas.

Numerosas características esenciales e intrínsecas del lenguaje humano son comunes al hombre de todas las sociedades. Forman una matriz universal que por ser compartida por todas las lenguas se denominan universales lingüisticos.

Lo que queda claro es que, por muy distintos que sean los aspectos del lenguaje, hay rasgos que se encuentran en todas las lenguas.

Esta teoría trae como consecuencia que, aun cuando todos los valores connotativos o visiones del mundo no sean transferibles de una lengua a otra, al menos pueden transferirse las denotaciones o universales lingüísticos.

\section{BIBLIOGRAFÍA}

- 'ABD AL-WAHHĀB BĀKIR et alii, al-Nahww al-carabīmin-jilāl al-nuṣūṣ, 2 vols., Túnez 1.984.

- 'ABD AL-WAHHĀB BĀKIR et alii, al-Ṣarf al-'arabī, Túnez 1.985.

- AL-'ADNĀNĪ, M., Murcyam al-aglat al-lugawiyya al-múāșira, Beirut 1.984.

- ALARCOS LLORACH, E., Gramática estructural, Madrid 1.969.

- ALARCOS LLORACH, E., Estudios de gramática funcional del español, Madrid 1.970.

- BACH, E., An Introduction to Transformational Grammar, New York 1.964.

- BACH, E.; HARMS, H., eds., Universals in Linguistic Theory, New York 1.968.

- BARTH, G., Recherches sur la fréquence et la valeur des parties du discours en français, en anglais et en espagnol, Paris 1.961.

- BENSE, M., Theorie der Texte, Köln 1.962. 
- BLOOMFIELD, L., "A set of postulates for the science of language", Linguistics, $\mathrm{n}^{\circ} 2$, 1.926, pp. 153-164.

- BRESNAN, ED., The Mental Representation of Grammatical Relations, Cambridge 1.982.

- BÜHLER, K., Teoría del lenguaje, Madrid 1.950.

- BULL, W., Applied Linguistics, New York 1.965.

- CATFORD, J.C., A Linguistic Theory of Translation, London 1.965.

- COHEN, D., "Les formes du predicat en arabe et la théorie de la phrase chez les anciennes grammairiens arabes", Mélanges M. Cohen, La Haye 1.970.

- CRYSTAL, D., Linguistics, Harmondsworth 1.971.

- CHAFE, Wallace L., "Language and symbolization", Linguistics, $\mathrm{n}^{\circ}$ 43, 1.967, pp. 57-91.

- CHAFE, Wallace L., Meanings and the Structure of Language, Chicago 1.970.

- CHOMSKY, N., Syntactic Structures, The Hague 1.957.

- CHOMSKY, N., Aspects of the Theory of Syntax, Cambridge 1.965.

- CHOMSKY, N., Language and Mind, New York 1.968.

- CHOMSKY, N., Studies on Semantics in Generative Grammar, The Hague 1.972.

- CHOMSKY, N., Lectures on Government and Binding, Foris Publications, Dordrecht 1.981.

- CHOMSKY, N., Some concepts and consequences of the theory of Government and Binding, Linguistic Inquiry Monographs, MIT Press 1.982.

- DAVIAULT, P., Langage et traduction, Ottawa 1.961.

- DELACROIX, H., Le langage et la pensée, Paris 1.930.

- DÉVÉNYI, K.; IVANYI, T., Proceedings of the Colloquium on Arabic Grammar, Budapest 1.991.

- DI PIETRO, Robert J., Language Structure in Contrast, Rowley Mass. 1.971.

- AL-FADLİ, 'A.H., Fahrasa al-kutub al-nahwiyya al-mațū̄ca, 1.986.

- AL-FĀSİ AL-FIHRİ, 'Abd al-Qādir, al-Lisāniyyat wa-l-luga al-carabiyya, 2 vols., Casablanca 1.985.

- AL-FĀSİ AL-FIHRĪ, 'Abd al-Qãdir, al-Bina' al-muwazī, Casablanca 1.988.

- GILI Y GAYA, S., Curso superior de sintaxis española, México 1.943.

- GOLDIN, Mark G., Spanish Case and Function, Washington, D.C. 1.968. 
- GREENBERG, Joseph H., Universals in Language, Cambridge 1.973.

- GRUBER, J.S., "Studies in Lexical Relations", Lexical Structures in Syntax and Semantics, Amsterdam 1.965.

- AL-HADİTİ, J., Abniya al-ṣarf fi-kitāb Sỉbawayh, Bagdad 1.965.

- HARRIS, Zellig S., "Discourse analysis", Linguistics, $\mathrm{n}^{\circ}$ 28, 1.952, pp. 1-30.

- HARRIS, Zellig S., String Analysis of Sentence Structure, The Hague 1.962.

- HUMBERT, G., Les voies de la transmission du Kitäb de Sibawayhi, Librería Científica General, 1.995.

- HJELMSLEV, L., Prolégomènes à une théorie du langage, Paris 1.968.

- HJELMSLEV, L., Essais linguistiques, Paris 1.971 (traducción española por Elena Bombín Izquierdo y Félix Piñero Torre, Ensayos lingüisticos, Madrid 1.972).

- IBN DURAYD, Kitāb yamhara al-luga, 3 tomos, ed. por Munīr Ba ${ }^{c}$ alabbak̄̄, Beirut s.f.

- JACKENDOFF, R., Syntax: A Study of Phrase Structures, Cambridge 1.977.

- JACOBS, Roderick A., Studies in Language, Waltham 1.973.

- JAKOBSON, R., Fundamentals of Language, The Hague 1.956.

- JAKOBSON, R., Linguistics and Communication Theory: Structure of Language and its Mathematical Aspects, Providence, American Mathematical Society, 1.961.

- KATZ, J.; POSTAL, Paul M., An Integrated Theory of Linguistic Descriptions, Cambridge 1.964.

- LANGACKER, Ronald W., Language and its Structure, New York 1.968.

- LESTER, M., Readings in Applied Transformational Grammar, New York 1.970.

- LYONS, J., Introduction to Theorical Linguistics, Cambridge 1.968.

- MARTINET, A., Quelques traits généraux de la syntaxe, Free University Quarterly 7.2., 1.959.

- MARTINET, A., Elements de linguistique générale, Paris 1.970.

- MARTINET, A., La linguistique synchronique, Paris 1.970.

- MASSIGNON, L., "Réflexions sur le structure primitive de l'analyse grammaticale en arabe", Arabica, I, 1.954.

- MILIC, Louis T., Stylistics on Style: A Handbook with Selections for Analysis, New York 1.969 .

- MOUNIN, G., Les problèmes théoriques de la traduction, Paris 1.963. 
- AL-MUTAWAKKIL, A., al-Wazā'if al-tadawuliyya fí l-luga al-'arabiyya, Casablanca 1.985 .

-AL-MUTAWAKKIL, A., Dirāsat fï-naḥw al-luga al-'arabiyya al-waziffi, Casablanca 1.986.

- AL-MUTAWAKKIL, A., Mina l-bunya al-camaliyya ilà l-bunya al-mukawwiniyya: alWazìifa-al-maf ül fi l-luga al-carabiyya, Casablanca 1.987.

- NIDA, Eugene A., Language Structure and Translation, Standford 1.975.

- POTTIER, B., Introduction à l'étude de la morphosyntaxe espagnole, Paris 1.966.

- POTTIER, B., Grammaire de l'espagnol, Paris 1.969.

- AL-RAHHĀLİ, M., al- ${ }^{c}$ Atf fî l-luga al--arabiyya min abhaț tahdīr šahada al-dirāsat alyāmiciyya al-culyà, 1.985 .

- ROMAN, A., Étude de la phonologie et de la morphologie de la koinè arabe, 2 tomos, Librería Científica General 1.983.

- SAPIR, E., Language: An Introduction to the Study of Speech, New York 1.921.

- SAUSSURE, F.de, Curso de lingüística general, traducción española por Amado Alonso, Buenos Aires 1.971, $9^{\mathrm{a}}$ edición.

- SINCLAIR, John McH., "A thecnique of stylistic description", Language and Style, $\mathrm{n}^{\circ} 1$, 1.968 , pp. 215-242.

- STOCKWELL, R.; BOWEN, J.; MARTIN, J., The Grammatical Structures of English and Spanish, Chicago 1.965.

- TESNIERE, L., Eléments de syntaxe structurale, Paris 1.959.

- THORNE, J.P., "Stylistics and generative grammar", Journal of Linguistics, $\mathrm{n}^{\circ}$ 1, 1.965, pp. 49-59.

- THORNE, J.P., "Generative grammar and stylistic analysis", New Horizons in Linguistics, editado por John Lyons, Middlesex 1.970.

- TRIER, J., Der Deutsche Wortschatz im Sinnbezirk des Verstandes, Heidelberg 1.931.

- WEINREICH, U., Languages in Contact, The Hague 1.963.

- ZAKARIYA, M., al-Alsuniyya al-tawlidiyya wa-l-tahwiliyya wa-qawã id al-luga alcarabiyya (al-yumla al-basița), Beirut 1.983. 
